\title{
Solution to the sorption hysteresis by novel compact composite multi-salt sorbents
}

\author{
J. Gao, L.W. Wang*, R.Z. Wang, Z.S. Zhou \\ Institute of Refrigeration and Cryogenic, Key Laboratory of Power Machinery and Engineering of \\ MOE, Shanghai Jiao Tong University, Shanghai, 200240, China \\ * Corresponding author. Email: lwwang@sjtu.edu.cn; Tel. +86-21-34208038; Fax.+86-21-34206814
}

\begin{abstract}
Two novel types of consolidated composite sorbents of $\mathrm{NH}_{4} \mathrm{Cl} / \mathrm{CaCl}_{2} / \mathrm{MnCl}_{2}$ and $\mathrm{NH}_{4} \mathrm{Cl} / \mathrm{CaCl}_{2}$ are developed by the matrix of expanded natural graphite treated with sulfuric acid (ENG-TSA). The Clapeyron curves and sorption / desorption properties of different sorbents are tested and compared under non-equilibrium conditions. Compared with single-salt sorbent, the multi-salt / ENG-TSA sorbents show the combining properties of each kind of metal chloride they contain. One novel phenomenon is discovered in the study is that the sorption hysteresis of single salts, which is regarded as one common phenomenon for chemisorption, can be changed by the composite sorbents of multi-salt. For the composite bi-salt sorbent of $\mathrm{NH}_{4} \mathrm{Cl} / \mathrm{CaCl}_{2}$ the sorption hysteresis is much less significant than the single metal chlorides of $\mathrm{NH}_{4} \mathrm{Cl}$ and $\mathrm{CaCl}_{2}$. For the tri-salt composite sorbent of $\mathrm{NH}_{4} \mathrm{Cl} / \mathrm{CaCl}_{2} / \mathrm{MnCl}_{2}$ the sorption hysteresis disappears. The reason is analyzed and it may be related to the resorption between the metal chlorides they contain, which leads to a reduction of reaction heat that is believed to be a typical reason for sorption hysteresis.
\end{abstract}

Key words: consolidated composite sorbent; multi-salt; non-equilibrium; sorption hysteresis

\section{Introduction}

The solid sorption refrigeration technology, with zero ODP (ozone depletion potential) and GWP (global warming potential), is a type of environmental benign and energy saving technology and attracted more and more attention in recent years. Compared with the vapor compression refrigeration system, it is believed that solid sorption refrigeration system has a simpler structure, less initial investment, lower operating costs and less noise [1, 2]. Solid 
sorption refrigeration had been investigated intensively for the recovery of solar energy and waste heat $[3,4]$.

The traditional intermittent solid sorption refrigeration system generally involves a sorption bed, an evaporator, and a condenser. The sorption bed desorbs in the heating and desorption process and the desorbed refrigerant condenses in a condenser, and the refrigeration effect is output by the evaporation of the refrigerant in an evaporator in sorption and refrigeration phase [5]. Two kinds of sorption technology are involved in the solid sorption, which are physical solid sorption termed as adsorption [6], and chemisorption for which sorption happens both on the surface and inside of sorbents, i.e. has both features of absorption and adsorption [7].

Studies on the solid sorption, both adsorption and chemisorption, mainly focus on the sorption materials, working pairs, and cycles. For example, T. Miyazaki et al. studied the adsorption system with the working pair of silica gel-water, and two kinds of silica gels were compared [8]. The new type of solid sorbent of zeolite $13 \mathrm{X} / \mathrm{CaCl}_{2}$ was developed by Alireza Sadeghlu for a two-bed system and it was proved with a better performance [9]. H.J. Dakkama et al. investigated the performance of various solid sorption working pairs with wide range of applications in sorption refrigeration systems [10]. Z. Tamainot-Telto et al. tried to design and develop a low cost rotary regenerative adsorption air conditioning system [11].

The metal halide-ammonia working pairs are the common working pairs for chemisorption refrigeration because ammonia complex can be formed easily with a wide range of driving heat source and works under positive pressure. On the research of the metal halide-ammonia working pairs, the sorption hysteresis was early found by V. Goetz and A. Marty [12]. After that some academics discussed the sorption hysteresis and it is recognized as a typical phenomenon for the chemisorption. Josée Trudel et al. observed pseudo-equilibrium hysteresis behavior and they thought the width of the hysteresis loop was a function of heating rate [13]. The stability of $\mathrm{CoCl}_{2} \cdot x \mathrm{NH}_{3}$ salt was found to be a function of temperature and pressure [14]. Furthermore, the synthesis and decomposition reactions were controlled by diff erent phenomena [15], which may probably cause the sorption hysteresis. Y. Zhong et al. did the research on the isothermal sorption characteristics of $\mathrm{BaCl}_{2}-\mathrm{NH}_{3}$ pair and used the van't Hoff diagram to describe the termination of synthesis and decomposition [16]. Recently 
Z.S. Zhou and L.W. Wang had studied the non-equilibrium performance of $\mathrm{NH}_{4} \mathrm{Cl}, \mathrm{CaCl}_{2}$ and $\mathrm{MnCl}_{2}$, and established the models especially for the desorption hysteresis [17]. It is recognized extensively that the sorption hysteresis is a common phenomenon and should be considered for the desorption process.

Recently we studied the new types of consolidated composite sorbents of multi-salt, and one interesting phenomenon is found that the sorption hysteresis will disappear with the reasonable combination of different salts. In this paper such a phenomenon is analyzed by the Clapeyron curves and isobaric sorption and desorption performances.

\section{Development of compact composite multi-salt sorbents}

Two types of the multi-salt composites are studied, which are bi-salt mixture with $\mathrm{NH}_{4} \mathrm{Cl}$ and $\mathrm{CaCl}_{2}$ and tri-salt mixture of $\mathrm{NH}_{4} \mathrm{Cl}, \mathrm{CaCl}_{2}$ and $\mathrm{MnCl}_{2}$.

According to the temperature of the driving heat source, $\mathrm{NH}_{4} \mathrm{Cl}, \mathrm{CaCl}_{2}$ and $\mathrm{MnCl}_{2}$ are classified as low-temperature salt (desorption temperature of $60 \sim 90^{\circ} \mathrm{C}$ ), mid-temperature salt (desorption temperature of $90 \sim 150^{\circ} \mathrm{C}$ ) and high-temperature salt (desorption temperature higher than $130 \sim 150^{\circ} \mathrm{C}$ ) respectively. Chlorides of non-crystalline water are used in the test. The matrix for the sorbents is expanded natural graphite treated by the sulfuric acid (ENG-TSA). ENG-TSA is made from natural graphite that is soaked in sulfuric acid, which become intercalated in the layered structure of the graphite. The sample is exfoliated by heating in a flame, forming expanded graphite with much lower density than normal ENG whilst the intercalated acid is removed. The compact ENG-TSA has been proved with high thermal conductivity and reasonable permeability. The maximum thermal conductivity measured is $337 \mathrm{~W} /(\mathrm{m} \cdot \mathrm{K})$ at a bulk density of $831 \mathrm{~kg} / \mathrm{m}^{3}$. The permeability perpendicular to the direction of compression vary in the range of $10^{-11}$ to $10^{-16} \mathrm{~m}^{2}$ as the density increases from 111 to $539 \mathrm{~kg} / \mathrm{m}^{3}$. As a type of heat transfer matrix the thermal diffusivity is about five times higher than that of pure aluminum [18].The development of the novel composite sorbents involves the following steps.

(1) Different metal chlorides and matrix, such as $\mathrm{NH}_{4} \mathrm{Cl}, \mathrm{CaCl}_{2}, \mathrm{MnCl}_{2}$ and TNG-TSA are dried in the oven for 3-4 h to dry up the water inside the sorbents and matrix. The 
temperature of the oven is controlled at $130^{\circ} \mathrm{C}$.

(2) The salts are weighted by the balance with accuracy of $0.01 \mathrm{~g}$, and then they are dissolved in water respectively. After that the ENG-TSA is mixed in the solution. For the bi-salt composite of $\mathrm{NH}_{4} \mathrm{Cl}$ and $\mathrm{CaCl}_{2}$, the ratio among $\mathrm{NH}_{4} \mathrm{Cl}, \mathrm{CaCl}_{2}$ and ENG-TSA is 2:2:1, and for the tri-salt mixture, the ratio among $\mathrm{NH}_{4} \mathrm{Cl}, \mathrm{CaCl}_{2}, \mathrm{MnCl}_{2}$ and ENG-TSA is 4:4:4:3. After the composite is uniformly mixed, the mixture is placed in an oven and dried 6-7 h at the temperature of $160^{\circ} \mathrm{C}$.

(3) The dried composite sorbent is compressed into blocks and the density is about 400 $\mathrm{kg} / \mathrm{m}^{3}$.

\section{Experimental unit and testing process}

The experimental test unit is mainly consisted of one sorption bed, one evaporator/condenser and one differential pressure transmitter. The detailed structure of the test unit is shown in reference [17]. The temperature of the sorption bed and evaporator / condenser is controlled by two thermostats.

The testing procedures of Clapeyron curves are as follows:

(1) The condenser is controlled at $-10^{\circ} \mathrm{C}$ and the highest desorption temperature is set at $180^{\circ} \mathrm{C}$. The refrigerant is desorbed from the sorption bed and condenses in the condenser. When the system reaches the equilibrium state, i.e. the level of the refrigerant inside condenser gets to the pre-set value and changes little, the desorption condensation process is completed. For such a state the $\mathrm{NH}_{3}$ sorbed by $\mathrm{NH}_{4} \mathrm{Cl}$ is

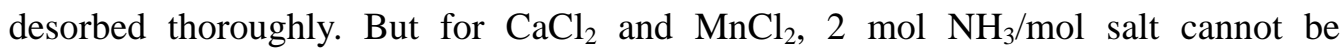
desorbed because the temperature isn't high enough for thoroughly desorption.

(2) Close the valve between the sorption bed and condenser, then the temperature of the high temperature thermostat is slowly decreased, and the sorption quantity, pressure, and temperature are recorded.

(3) When the temperature decreases to the lowest sorption temperature, open the valve between sorption bed and evaporator, and get a new pre-set data for sorption quantity. 
After that closed the valve, and change the temperature of sorption bed. A new Clapeyron curve can be gotten by recording the data of sorption quantity, temperature and pressure.

(4) The above procedures are repeated and all the Clapeyron curves under different conditions can be gotten.

Taking the evaporating/condensing temperature of $-10^{\circ} \mathrm{C}$ as one example, the testing procedures of isobaric sorption and desorption performance are as follows:

(1) The evaporating/condensing temperature is set at $-10^{\circ} \mathrm{C}$. Open the valve between the evaporator/condenser and sorption bed, and let the sorption bed sorbs the refrigerant to the maximum sorption quantity. Record the initial sorption quantity.

(2) Heat the sorption bed by the step of $5-8^{\circ} \mathrm{C}$. The desorption will happen when the temperature of the sorption bed increases. The temperature inside the sorption bed and sorption data are recorded for each set sorption temperature when the sorption quantity tested by the differential pressure transmitter changes little for five minutes, and the isobaric desorption curve is gotten.

(3) When the desorption temperature gets to the highest desorption temperature, the sorption bed is cooled by the thermostat, and the temperature decreases slowly. The sorption between sorption bed and evaporator will happen and the temperature and sorption data are recorded when the data collected by the differential pressure transmitter changes little for five minutes. The isobaric sorption curve is gotten.

(4) The evaporating/condensing temperature is adjusted from $-10^{\circ} \mathrm{C}$ to $25^{\circ} \mathrm{C}$ by the step of $5^{\circ} \mathrm{C}$, and the steps 1-2 are repeated. Then all isobaric desorption/sorption curves are obtained.

The sorption quantity of sorbent is calculated by the refrigerant level in the condenser/evaporator, and the equation is:

$$
x=\frac{1}{m} \cdot\left\{\left[1-\frac{v^{\prime}\left(T_{e}\right)}{v^{\prime \prime}\left(T_{e}\right)}\right] \cdot \frac{A_{\mathrm{e}}}{g} \cdot \Delta(\Delta p)+\frac{\Delta V}{v^{\prime \prime}\left(T_{e}\right)}\right\}
$$

where $x$ is sorption quantity $\left(\mathrm{kg} \mathrm{kg}^{-1}\right), \Delta p$ is the pressure difference between the two ends of ammonia column, $\Delta(\Delta p)$ is the difference between the data in sorption/desorption process and 
the initial data $(\mathrm{Pa}), m$ is the sorbent mass $(\mathrm{kg}), A e$ is the effective area of cross section of ammonia in the evaporator / condenser $\left(\mathrm{m}^{2}\right), g$ is the gravity acceleration $\left(9.80 \mathrm{~m} \cdot \mathrm{s}^{-2}\right), v^{\prime}(\mathrm{Te})$ and $v^{\prime \prime}(\mathrm{Te})$ are specific volume of saturated liquid ammonia and saturated vapor ammonia $\left(\mathrm{m}^{3} \cdot \mathrm{kg}^{-1}\right), \Delta V$ is the volume from the outlet of the accumulator to the inside of the bed $\left(\mathrm{m}^{3}\right)$, and it is only considered for the first sorption process because it is vacuum. For the following experiments it can be neglected because the channel is filled by the ammonia vapor and the change of the specific volume of the ammonia vapor is very small and can be neglected.

The sorbent mass is measured by the balance (BS2202S) with a measuring error of $0.01 \mathrm{~g}$. The pressure difference between the vapor end and liquid end of the evaporator / condenser is tested by the smart differential pressure transmitter, whose testing error is $0.2 \%$. According to Eq. (2), shown as follows:

$$
\begin{gathered}
|\mathrm{d} x|=\left|-\left(1-\frac{\nu^{\prime}\left(T_{\mathrm{e}}\right)}{v^{\prime \prime}\left(T_{\mathrm{e}}\right)}\right) \cdot \frac{A_{e} \times \mathrm{d} m}{m^{2} \cdot g} \cdot \Delta(\Delta p)+\left(1-\frac{\nu^{\prime}\left(T_{\mathrm{e}}\right)}{v^{\prime \prime}\left(T_{\mathrm{e}}\right)}\right) \cdot \frac{A_{e}}{m \cdot g} \cdot \mathrm{d}(\Delta(\Delta p))\right| \\
\left|\frac{\mathrm{d} x}{x}\right| \leq\left|\frac{\mathrm{d} m}{m}\right|+\frac{\mathrm{d}(\Delta(\Delta p))}{\Delta(\Delta p)}
\end{gathered}
$$

Neglected the error caused by the last item in eq.(2), the maximum relative error of sorption / desorption quantity of sorbent is about $0.37 \%$.

\section{Characteristics of single salt-ammonia working pair}

\subsection{The Clapeyron curves under non-equilibrium conditions}

The Clapeyron curves of $\mathrm{NH}_{4} \mathrm{Cl}, \mathrm{CaCl}_{2}$ and $\mathrm{MnCl}_{2}$ are shown in Fig. 1 [17]. Fig. 1a shows that the curves of 4 to $6 \mathrm{~mol} \mathrm{NH}_{3} / \mathrm{mol} \mathrm{CaCl}_{2}$ are almost coincided with the theoretical line. The curves of $7 \mathrm{~mol}$ and $8 \mathrm{~mol} \mathrm{NH} / \mathrm{mol} \mathrm{CaCl}_{2}$ are extremely close to each other. That may be related to the stability constant. Suppose the stability constants of $4 \mathrm{~mol}, 6 \mathrm{~mol}$ and $8 \mathrm{~mol}$ are $k_{1}, k_{2}$ and $k_{3}$, the unstable constants are $1 / k_{1}, 1 / k_{2}$ and $1 / k_{3}$ respectively. The total stability constant for sorption from $6 \mathrm{~mol}$ to $8 \mathrm{~mol}$ is $k_{3} \times k_{2} \times k_{1}$, and the unstable constant of desorption of $8 \mathrm{~mol}$ to $6 \mathrm{~mol}$ is $1 / k_{3}$. It isn't equal to $k_{3} \times k_{2} \times k_{1}$, that means a big difference between the speed of dissociation and synthesis. Therefore, the curves of low complexation capacity are close to the theoretical line. Viewed from another aspect, the complex of 4 mol uses $\mathrm{sp}^{3}$ 
hybrid orbitals and has a structure of regular tetrahedron. Compared with it, the sorption of 6 and $8 \mathrm{~mol} \mathrm{NH}_{3}$ enters $d$ orbitals and the complex form regular octahedron and dodecahedron. Due to the different structure of the complex, the equilibrium temperature may be different [19]. The deviation from the theoretical line is larger when the sorption quantity of ammonia is larger. Such a phenomenon indicates that the non-equilibrium performances are much different from equilibrium results which are mono-variant dependent. Fig. $1 \mathrm{~b}$ is for the working pair of $\mathrm{MnCl}_{2}-\mathrm{NH}_{3}$. Similarly, when the sorption quantity is the smallest, which is 2 mol $\mathrm{NH}_{3} / \mathrm{mol} \mathrm{MnCl}_{2}$, the curve is coincident with the theoretical line, otherwise the line deviates from the theoretical line more seriously when the sorption quantity is larger. The results of $\mathrm{NH}_{4} \mathrm{Cl}-\mathrm{NH}_{3}$ are much different from the $\mathrm{MnCl}_{2}-\mathrm{NH}_{3}$ and $\mathrm{CaCl}_{2}-\mathrm{NH}_{3}$. The sorption line of $1 \mathrm{~mol} \mathrm{NH}_{3} / \mathrm{mol} \mathrm{NH}_{4} \mathrm{Cl}$ in Fig. 1c is at the right side of the theoretical line and such a phenomenon may relate with the condensation and evaporation process of $\mathrm{NH}_{3}$ inside the ENG-TSA. The data shown in Fig. 1 indicates that the chemisorption performance is not controlled by a single variable, namely temperature or pressure, and it is determined by two parameters of pressure and temperature.

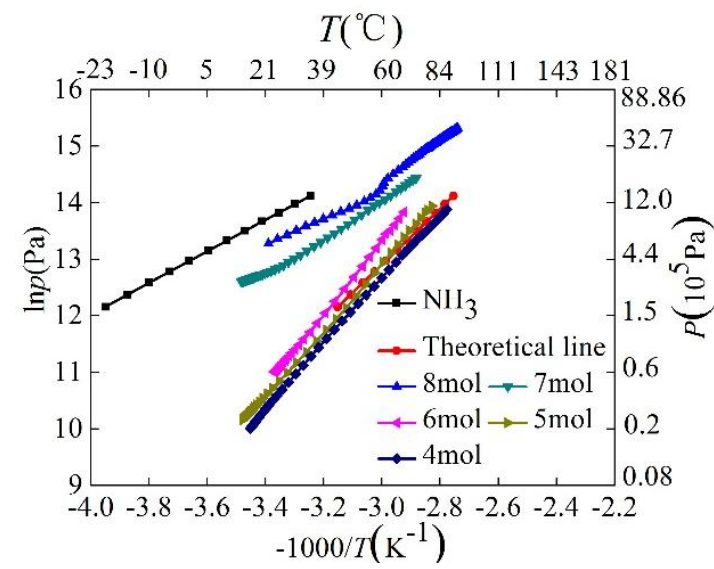

(a)

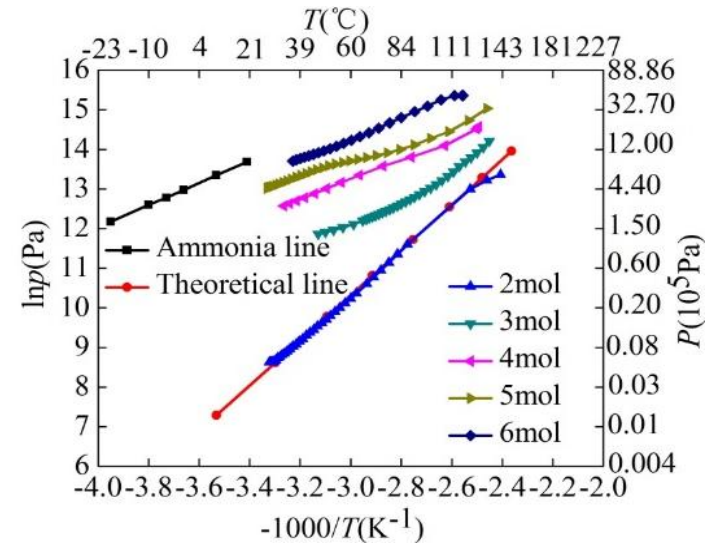

(b) 


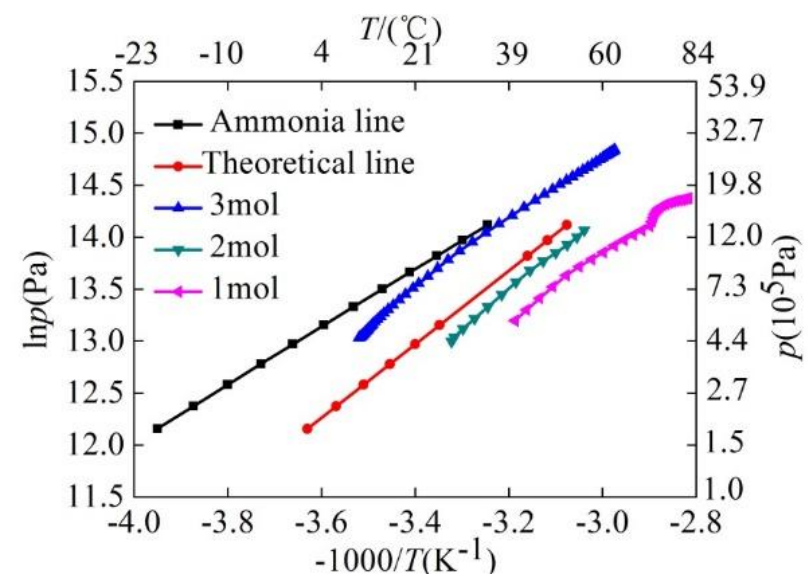

(c)

Fig. 1 The Clapeyron diagram of single-salt under non-equilibrium conditions: (a) $\mathrm{CaCl}_{2}-\mathrm{NH}_{3}$, (b) $\mathrm{MnCl}_{2}-\mathrm{NH}_{3}$, (c) $\mathrm{NH}_{4} \mathrm{Cl}-\mathrm{NH}_{3}$

\subsection{The sorption hysteresis phenomena of single-salt}

The sorption hysteresis can be seen clearly in Fig. 2, which is for the isobaric sorption / desorption processes of three kinds of single-salt- $\mathrm{NH}_{3}$ working pair when the evaporation / condensing pressure is $430 \mathrm{kPa}$.

Because of the big difference between desorption activation energy and sorption activation energy [20], i.e. the desorption activation energy of $\mathrm{CaCl}_{2}$ equals to the sum of the desorption activation energy and sorption heat and it is much larger than that of sorption phase, so the sorption hysteresis is serious for sorption/desorption process, just like Fig.2a shows. Similar conclusions can also be gotten from Fig. $2 \mathrm{~b}$ and 2c, i.e. $\mathrm{MnCl}_{2}$ and $\mathrm{NH}_{4} \mathrm{Cl}$.

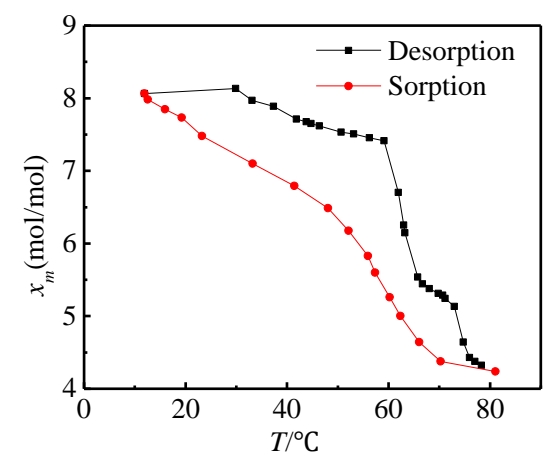

(a)

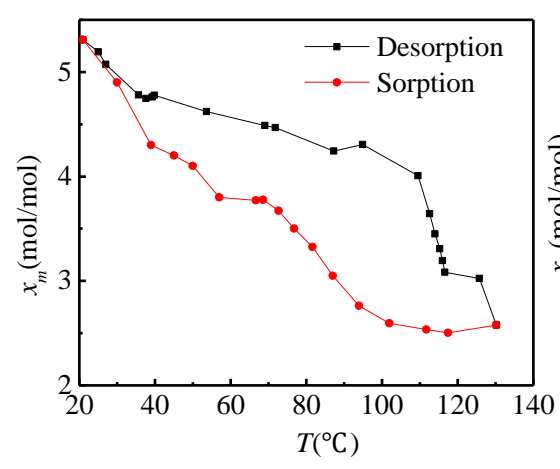

(b)

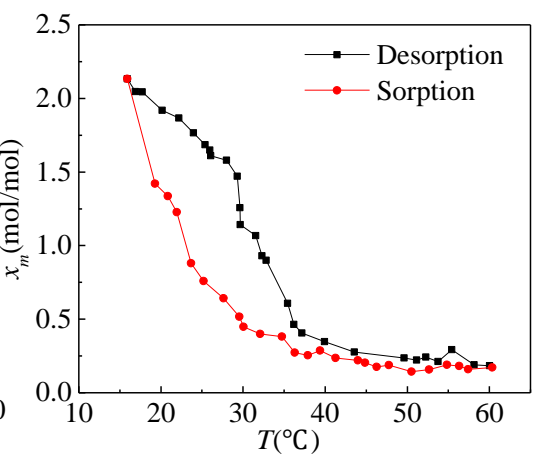

(c)

Fig. 2 The isobaric sorption/desorption curves of single-salt: (a) $\mathrm{CaCl}_{2}$, (b) $\mathrm{MnCl}_{2}$, (c) $\mathrm{NH}_{4} \mathrm{Cl}$ 


\section{Characteristics of the bi-salt mixtures}

For the bi-salt mixture of $\mathrm{NH}_{4} \mathrm{Cl} / \mathrm{CaCl}_{2}$, the temperature and pressure are tested under the condition of different sorption quantities, and the results are compared with the theoretical Clapeyron curves of the single salts of $\mathrm{CaCl}_{2}$ and $\mathrm{NH}_{4} \mathrm{Cl}$. As shown in Fig. 3, for the bi-salt mixture, when the sorption quantity is about $4.6 \mathrm{~mol} \mathrm{NH}_{3} / \mathrm{mol}$ chloride, the curve roughly coincides with the theoretical Clapeyron curve of $\mathrm{NH}_{4} \mathrm{Cl}$. When the sorption quantity is low, for example for the lowest sorption quantity of $0.7 \mathrm{~mol} \mathrm{NH}_{3} / \mathrm{mol}$ chloride, the curve is close to the Clapeyron curve of $\mathrm{CaCl}_{2} / 4-2$ under equilibrium conditions.

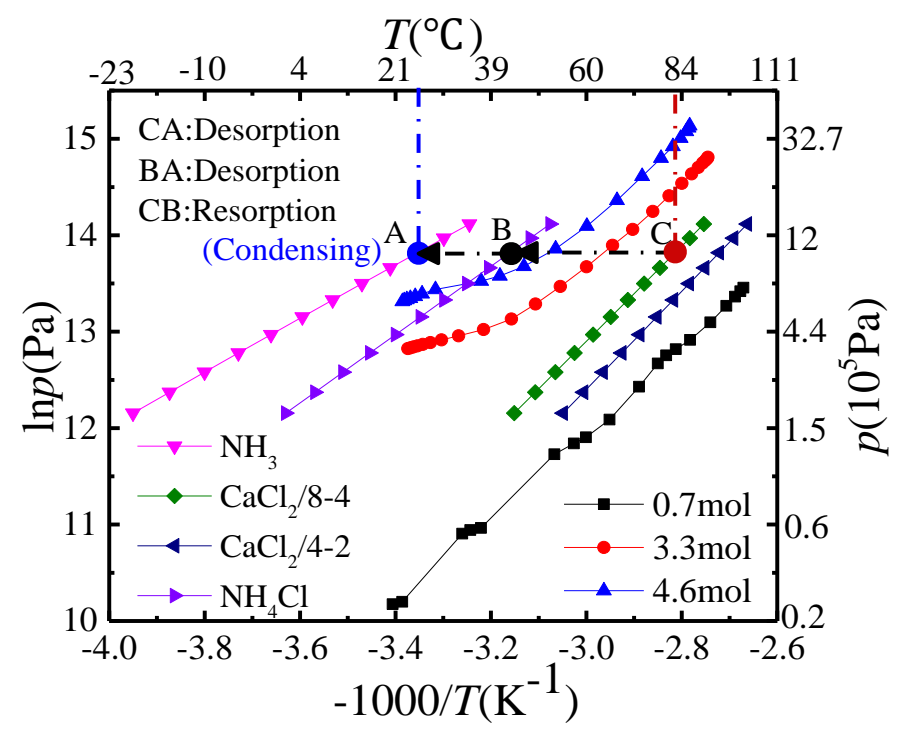

Fig. 3 The Clapeyron diagram of bi-salt under non-equilibrium conditions

The sorption hysteresis phenomenon is studied for the bi-salt mixture, and the isobaric sorption/desorption performances under the condition of different pressures are shown in Fig.4. 


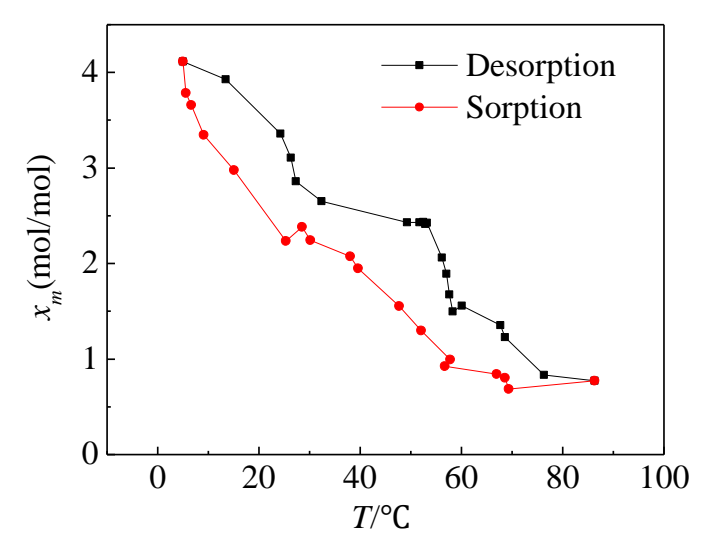

(a)

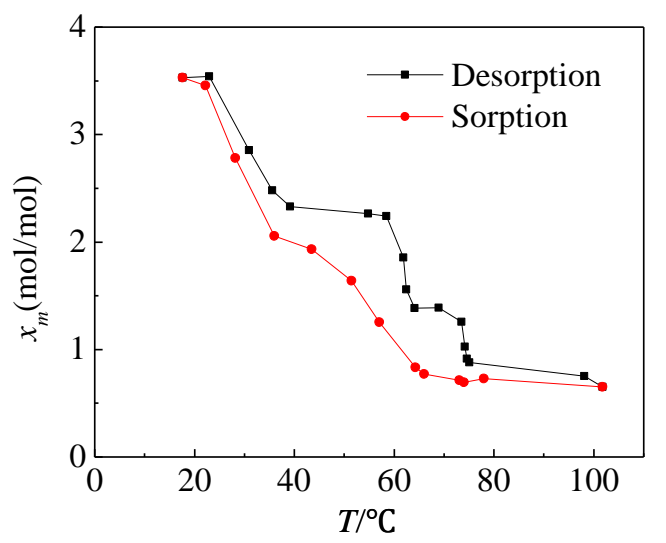

(b)

Fig. 4 The isobaric sorption/desorption curves of bi-salt: (a) $360 \mathrm{kPa}$, (b) $430 \mathrm{kPa}$

As Fig. 4a shows, there is a step starts from $20^{\circ} \mathrm{C}$ and ends at about $58^{\circ} \mathrm{C}$ for the bi-salt mixture at the pressure of $360 \mathrm{kPa}$. According to the theoretical Clapeyron curves under equilibrium condition, shown in Fig.1, the pressure and temperature are one-to-one. Since the pressure is $360 \mathrm{kPa}$, the level of $360 \mathrm{kPa}$ intersects with the theoretical curves of $\mathrm{NH}_{4} \mathrm{Cl}$ and $\mathrm{CaCl}_{2}$, the corresponding temperature is about $16^{\circ} \mathrm{C}$ and $57^{\circ} \mathrm{C}$, respectively. So it can be concluded from Fig.4a that the mixture shows combining properties of two kinds of metal chlorides it contains. Similar conclusion can be obtained from Fig.4b. Fig.4a and $4 \mathrm{~b}$ show that the sorption hysteresis phenomena for different pressures are similar, and it is much less significant than that of the single salt sorbents, as shown in Fig.2. The reason for that is analyzed by taking points A, B and C in Fig. 3 as the example. Supposing $\mathrm{NH}_{3}$ is desorbing from $\mathrm{CaCl}_{2}$ at a certain pressure and temperature, then in Fig. 3 the desorption point is $\mathrm{C}$ and the condensation point is A. The desorption line CA intersects with the theoretical curves of $\mathrm{NH}_{4} \mathrm{Cl}$ at point $\mathrm{B}$. For bi-salt three processes may proceed. First one is process $\mathrm{C} \rightarrow \mathrm{A}$, for which the $\mathrm{NH}_{3}$ desorbs from $\mathrm{CaCl}_{2}$; The second process $\mathrm{B} \rightarrow \mathrm{A}$, for which the $\mathrm{NH}_{3}$ is desorbing from $\mathrm{NH}_{4} \mathrm{Cl}$. The last process $\mathrm{C} \rightarrow \mathrm{B}$ is the most interesting one, which is the resorption between $\mathrm{CaCl}_{2}$ and $\mathrm{NH}_{4} \mathrm{Cl}$. For resorption process the reaction heat releases outside by $\mathrm{NH}_{4} \mathrm{Cl}$. Part of the desorption heat and sorption heat may be neutralized, which leads to a reduction of the total reaction heat. Since hysteresis is believed relate to reaction heat for desorption process as mentioned by various researchers [17], the reduction may make sorption hysteresis not as serious as single salt. So it can be concluded that multi-salt may 
become a solution for solving the hysteresis phenomenon that happens commonly for the single salt. In order to verify that the tri-salt is studied.

\section{Characteristics of the tri-salt mixture}

\subsection{The Clapeyron curves under non-equilibrium conditions}

The Clapeyron curves of the tri-salt mixture are tested and the results are shown in Fig.5.

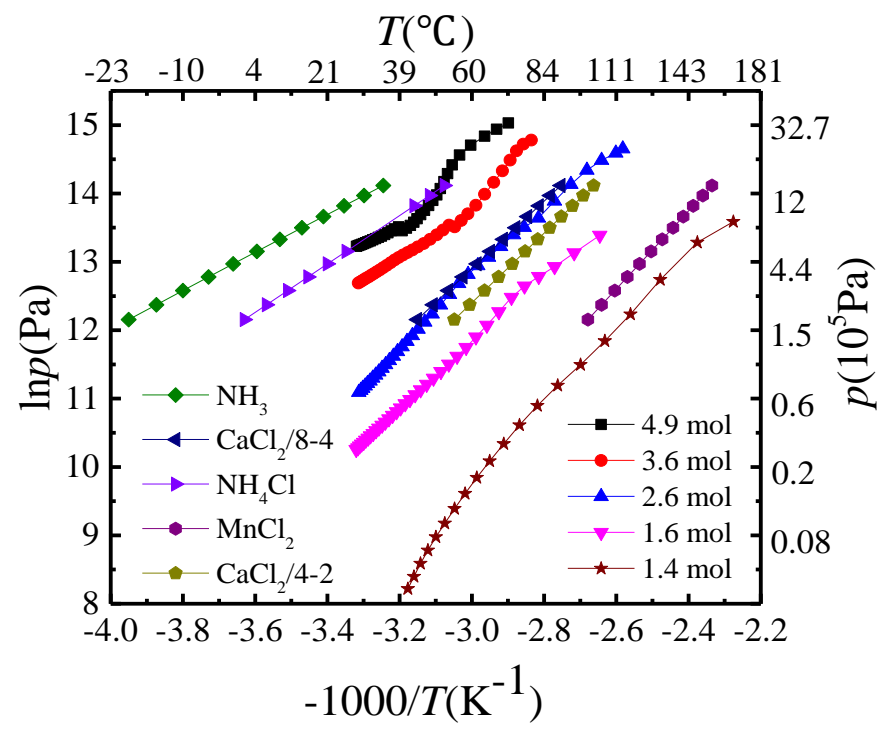

Fig. 5 The Clapeyron diagram of tri-salt mixture under non-equilibrium conditions

Similar with the performances of bi-salt mixture, the curve of high sorption quantity, such as $4.9 \mathrm{~mol}$ ammonia/mol mixture coincides with the theoretical Clapeyron curve of low temperature salt of $\mathrm{NH}_{4} \mathrm{Cl}$, and the curve of the lowest sorption quantity, which is $1.4 \mathrm{~mol}$ $\mathrm{NH}_{3} / \mathrm{mol}$ mixture, is close to the theoretical curve of high temperature salt of $\mathrm{MnCl}_{2}$. The curve of about $2.6 \mathrm{~mol} \mathrm{NH}_{3} / \mathrm{mol}$ mixture coincides with the theoretical Clapeyron curve of $\mathrm{CaCl}_{2}$ and reflect the properties of the mid-temperature salt. As the temperature increases, the spacing between the experimental curves grows. It shows that the less amount of ammonia the metal chlorides complexed, the greater energy required for desorption, i.e. the desorption becomes much more difficult. Such a phenomenon indicates again that the chemisorption process is bi-variant other than mono-variant controlled.

Fig. 3 and Fig. 5 indicate that the multi-salt sorbent's performance is related with the 
composites of different salts it includes. Because different properties of metal chlorides influence each other and the energy needed for full desorption may be different from the sum of all metal chlorides it contains, and that will have an influence on the sorption hysteresis phenomenon.

\subsection{Sorption hysteresis phenomena of tri-salt mixture}

The isobaric sorption / desorption characteristics for the pressures of $360 \mathrm{kPa}$ and $430 \mathrm{kPa}$ are studied, and the results are shown in Fig.6.

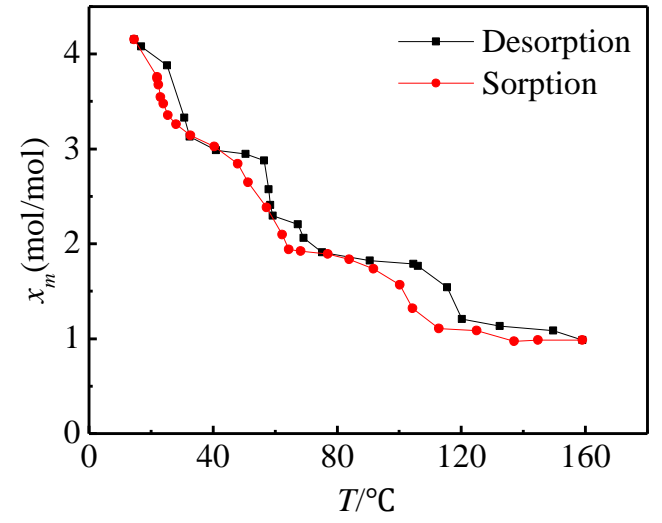

(a)

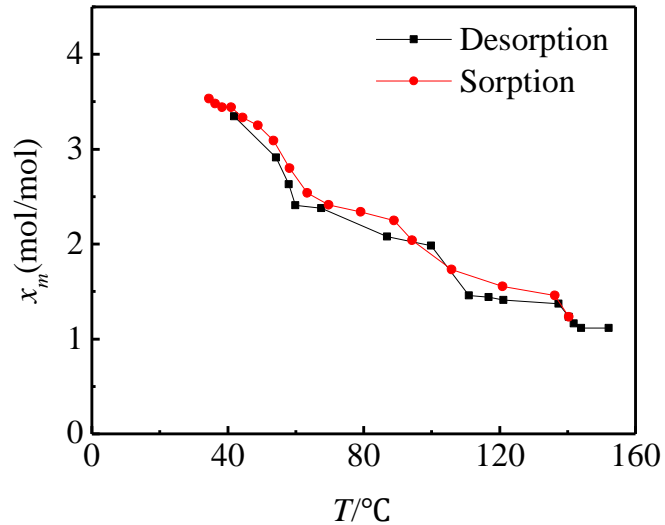

(b)

Fig. 6 The isobaric sorption/desorption curves of tri-salt: (a) $360 \mathrm{kPa}$, (b) $430 \mathrm{kPa}$

Three steps can be seen clearly in Fig. $6 a$ and $6 b$. The turning points for different pressure close to the equilibrium data of different chlorides. For example, for the working pressure of $360 \mathrm{kPa}$ shown in Fig.5, the equilibrium temperatures for Clapeyron curves are about $16^{\circ} \mathrm{C}$, $57^{\circ} \mathrm{C}, 69^{\circ} \mathrm{C}$ and $116^{\circ} \mathrm{C}$ respectively for the chlorides of $\mathrm{NH}_{4} \mathrm{Cl} / 3-0, \mathrm{CaCl}_{2} / 8-4, \mathrm{CaCl}_{2} / 4-2$ and $\mathrm{MnCl}_{2} / 6-2$. The corresponding turning temperatures in Fig. 6 a are $20^{\circ} \mathrm{C}, 60^{\circ} \mathrm{C}$ and $120^{\circ} \mathrm{C}$ separately, which are similar with the data of single-salt.

One novel phenomenon happened for the multi-salt mixture shown in Fig.6 is that the hysteresis doesn't exist this time. Just like discussed, the hysteresis had been found by V. Goetz and A. Marty early [12], and then L.W. Wang [21], Josée Trudel et al. [13], Z. Aidoun and M. Ternan [15] had discussed it. Generally the academics thought that the hysteresis is a common phenomenon and happened for almost all types of chemical sorbents. Fig. 6 gives a solution for the phenomenon and shows that the multi-salts can make the hysteresis disappear. 
When the pressure changes, Fig.6a and $6 \mathrm{~b}$ both don't have hysteresis loop which is shown previously in Fig.2 and Fig.4. Especially for the working pressure of $430 \mathrm{kPa}$, the sorption curve is almost overlapped on the desorption curve. Similar to the bi-salt sorbent, it should be related with decreased reaction heat. The resorption between $\mathrm{NH}_{4} \mathrm{Cl}, \mathrm{CaCl}_{2}$ and $\mathrm{MnCl}_{2}$ may leads to a reduction of the energy difference. Sorption and desorption of tri-salt sorbent will be much more complicated and may make the energy difference during sorption and desorption change a lot. So the sorption hysteresis disappear completely. But each salt maintains its intrinsic properties thanks to the physical mixing.

\section{Conclusions}

Two types of consolidated composite multi-salt sorbents are investigated and compared with single-salt sorbents. The detailed conclusions are as follows:

(1) The Clapeyron diagrams and sorption/desorption curves of bi-salt and tri-salt show that the properties of multi-salt mixture are the combination of that of single salts. For example, for tri-salt of $\mathrm{NH}_{4} \mathrm{Cl} / \mathrm{CaCl}_{2} / \mathrm{MnCl}_{2}$, its Clapeyron curves of some special sorption quantities coincide with the theoretical curve of $\mathrm{NH}_{4} \mathrm{Cl}, \mathrm{CaCl}_{2}$ and $\mathrm{MnCl}_{2}$ respectively. Besides, its each step in sorption/desorption curves is close to the data of single salts of $\mathrm{NH}_{4} \mathrm{Cl}, \mathrm{CaCl}_{2}$ and $\mathrm{MnCl}_{2}$ respectively at different heat source temperature.

(2) The sorption hysteresis of the bi-salt of $\mathrm{NH}_{4} \mathrm{Cl} / \mathrm{CaCl}_{2}$ sorbent is not as significant as that of the single salts it contains. And there is almost no sorption hysteresis in the consolidated composite sorbent of $\mathrm{NH}_{4} \mathrm{Cl} / \mathrm{CaCl}_{2} / \mathrm{MnCl}_{2}$ especially when the evaporation / condensing pressure is about $430 \mathrm{kPa}$. It proves that the sorption hysteresis can be solved by multi-salt sorbents.

(3) The multi-salt can make the sorption hysteresis phenomena disappear, and this phenomenon may relate with the decreased reaction heat which is caused by the resorption between LTS, MTS and HTS. But it requires further verification by the experiments on the desorption heat. 


\section{Acknowledgements}

This research was supported by the National Science Foundation of China (Grant No. 51576120), and the National Scientific and Technological Project for Rural Area during the Twelfth Five-year Plan Period (2015BAL04B04).

\section{References}

[1] V.K. Sharma, E.A. Kumar, S.S. Murthy, Influence of dynamic operating conditions on the performance of metal hydride based solid sorption cooling systems, Int. J. Hydrogen Energy. 40 (2015) 1108-1115.

[2] K.E. N'Tsoukpoe, D. Yamegueu, J. Bassole, Solar sorption refrigeration in Africa, Renew. Sust. Energ. Rev. 35 (2014) 318-335.

[3] I. Sarbu, C. Sebarchievici, General review of solar-powered closed sorption refrigeration systems, Energy Convers. Manage. 105 (2015) 403-422.

[4] P. Goyal, P. Baredar, A. Mittal, A.R. Siddiqui, Adsorption refrigeration technology - An overview of theory and its solar energy applications, Renew. Sust. Energ. Rev. 53 (2016) 1389-1410.

[5] R.Z. Wang, L.W. Wang, J.Y. Wu, Adsorption refrigeration theory and applications, Science Press, Beijing, 2007.

[6] H.Z. Hassan, A.A. Mohamad, A review on solar-powered closed physisorption cooling systems, Renew. Sust. Energ. Rev. 16 (2012) 2516-2538.

[7] F. Kuznik, K. Johannes, A review on chemisorption heat storage in low-energy buildings, Energy Procedia. 57 (2014) 2333-2341.

[8] T. Miyazaki, A. Akisawa, B.B. Saha, I.I. El-Sharkawy, A. Chakraborty, A new cycle time allocation for enhancing the performance of two-bed adsorption chillers, Int. J. Refrig. 32 (2009) 846-853.

[9] A. Sadeghlu, M. Yari, S.M.S. Mahmoudi, H.B. Dizaji, Performance evaluation of zeolite $13 \mathrm{X} / \mathrm{CaCl}_{2}$ two-bed adsorption refrigeration system, Int. J. Therm. Sci. 80 (2014) 76-82.

[10] H.J. Dakkama, A. Elsayed, R.K. AL-Dadah, S. Mahmoud, P. Youssef, Investigation of 
cascading adsorption refrigeration system with integrated evaporator-condenser heat exchanger using different working pairs, Energy Procedia. 75 (2015) 1496-1501.

[11] Z. Tamainot-Telto, R.E. Critoph, Advanced solid sorption air conditioning modules using monolithic carbon-ammonia pair, Appl. Therm. Eng. 23 (2003) 659-674.

[12] V. Goetz, A. Marty, A model for reversible solid-gas reactions submitted to temperature and pressure constraints: simulation of the rate of reaction in solid-gas reactor used as chemical heat pump, Chem. Eng. Sci. 47 (1992) 4445-4454.

[13] J. Trudel, S. Hosatte, M. Ternan, Solid-gas equilibrium in chemical heat pumps: the $\mathrm{NH}_{3}$ - $\mathrm{CoCl}_{2}$ system, Appl. Therm. Eng. 19 (1999) 495-511.

[14] Z. Aidoun, M. Ternan, Pseudo-stable transitions and instability in chemical heat pumps: the $\mathrm{NH}_{3}-\mathrm{CoCl}_{2}$ system, Appl. Therm. Eng. 21 (2001) 1019-1034.

[15] Z. Aidoun, M. Ternan, The synthesis reaction in a chemical heat pump reactor filled with chloride salt impregnated carbon fibres: the $\mathrm{NH}_{3}-\mathrm{CoCl}_{2}$ system, Appl. Therm. Eng. 22 (2002) 1943-1954.

[16] Y. Zhong, R.E. Critoph, R.N. Thorpe, Z. Tamainot-Telto, Y.I. Aristov, Isothermal sorption characteristics of the $\mathrm{BaCl}_{2}-\mathrm{NH}_{3}$ pair in a vermiculite host matrix, Appl. Therm. Eng. 27 (2007) 2455-2462.

[17] Z.S. Zhou, L.W. Wang, L. Jiang, P. Gao, R.Z. Wang, Non-equilibrium sorption performances for composite sorbents of chlorides - ammonia working pairs for refrigeration, Int. J. Refrig. 65 (2015) 60-68.

[18] L.W. Wang, S.J. Metcalf, R.E. Critoph, R. Thorpe, Z. Tamainot-Telto, Thermal conductivity and permeability of consolidated expanded natural graphite treated with sulphuric acid, Carbon. 49 (2011) 4812-4819.

[19] L.W. Wang, R.Z. Wang, R.G. Oliveira, A review on adsorption working pairs for refrigeration, Renew. Sust. Energ. Rev. 13 (2009) 518-534.

[20] Y.H. Zhang, Adsorption, Shanghai Scientific \& Technical Publishers, Shanghai, 1989.

[21] L.W. Wang, R.Z. Wang, J.Y. Wu, K. Wang, Studies on chemical adsorption hysteresis for adsorption refrigeration, J. Eng. Thermophys-Rus. 6 (2005) 901-904. 


\section{Figures:}

Fig. 1 The Clapeyron diagram of single-salt under non-equilibrium conditions: (a) $\mathrm{CaCl}_{2}-\mathrm{NH}_{3}$, (b) $\mathrm{MnCl}_{2}-\mathrm{NH}_{3}$, (c) $\mathrm{NH}_{4} \mathrm{Cl}-\mathrm{NH}_{3}$

Fig. 2 The isobaric sorption / desorption curves of single-salt: (a) $\mathrm{CaCl}_{2}$, (b) $\mathrm{MnCl}_{2}$, (c) $\mathrm{NH}_{4} \mathrm{Cl}$

Fig. 3 The Clapeyron diagram of bi-salt under non-equilibrium conditions

Fig. 4 The isobaric sorption/desorption curves of bi-salt: (a) $360 \mathrm{kPa}$, (b) $430 \mathrm{kPa}$

Fig. 5 The Clapeyron diagram of tri-salt under non-equilibrium conditions

Fig. 6 The isobaric sorption/desorption curves of tri-salt: (a) $360 \mathrm{kPa}$, (b) $430 \mathrm{kPa}$ 